Additional services for Cardiology in the Young:

Email alerts: $\underline{\text { Click here }}$

Subscriptions: $\underline{\text { Click here }}$

Commercial reprints: Click here

Terms of use : $\underline{\text { Click here }}$

\title{
The morphologic variability in atrioventricular valvar atresia
}

Robert H. Anderson, Siew Yen Ho and Michael L. Rigby

Cardiology in the Young / Volume 10 / Issue 01 / January 2000, pp 32 - 41

DOI: 10.1017/S1047951100006351, Published online: 19 August 2008

Link to this article: http://journals.cambridge.org/abstract S1047951100006351

How to cite this article:

Robert H. Anderson, Siew Yen Ho and Michael L. Rigby (2000). The morphologic variability in atrioventricular valvar atresia. Cardiology in the Young,10, pp 32-41 doi:10.1017/S1047951100006351

Request Permissions : $\underline{\text { Click here }}$ 
Cardiol Young 2000; 10: 32-41

(C) Greenwich Medical Media Ltd.

ISSN 1047-9511

\title{
Continuing Medical Education
}

\section{The morphologic variability in atrioventricular valvar atresia}

\author{
Robert H. Anderson, * Siew Yen Ho and Michael L. Rigby \\ *Cardiac Unit, Institute of Child Health, University College, London, UK; Paediatrics, National Heart \& Lung Institute, \\ Royal Brompton Campus, Imperial College School of Medicine, London, UK
}

$\mathrm{T}$ HE ESSENCE OF HEARTS WITH ATRIOVENTRICULAR valvar atresia is that, of necessity, there is complete admixture of systemic and pulmonary venous returns at atrial level, since one of the atriums has no direct communication with the ventricular mass. Traditionally, for the purposes of clinical diagnosis, such hearts are divided into the categories of tricuspid and mitral atresia. Within the context of this division, the essence of tricuspid atresia is complete blockage of the direct ventricular return of the systemic venous pathways. Mitral atresia, when used in this fashion, invokes the picture of the complete obstruction of direct pulmonary venous return. The potential anatomic substrates which can produce these haemodynamic arrangements, however, are complicated. This is because, in some situations, blockage of direct return of the systemic venous pathways can be produced by an atretic valve which, rather than being a tricuspid valve, has the morphology of the mitral valve. Similarly, in other cases, it is atresia of a morphologically tricuspid valve, rather than a mitral valve, which can block completely the direct ventricular egress from the pulmonary venous atrium. There are then further complexities concerning the underlying anatomic substrates. This is because, although an imperforate valvar membrane has traditionally been considered the exemplar of valvar atresia, examination of specimens in the majority of cases with tricuspid atresia shows that the valve itself, along with its supporting atrioventricular junction, has failed totally to form during cardiac development (Fig. 1). The morphologic feature underscoring the valvar atresia is absence of the atrioventricular

Correspondence to: Prof R.H. Anderson, Cardiac Unit, Instıtute of Chuld Health, 30 Guilford Street, London WCIN 1EH, UK. Tel: 0207905 2295; Fax: 0207905 2324; E-manl: R.Anderson@ich.ucl.ac.uk

Accepted for publication 20 August 1999 connection (Fig. 2). Identification of the valve involved as being morphologically tricuspid, or mitral as the case may be, is based upon inferences concerning the presumed embryogenesis of the ventricular mass. It is not possible to distinguish the morphology of the valve which is missing on the basis of the anatomy of the atretic atrium. Such a situation is less than ideal, and gives appreciable potential for disagreement.

The overall understanding of the nature of atrioventricular valvar atresia is then clouded still further by ongoing morphological controversies. Some still seem reticent to accept the concept of absence of one atrioventricular connection as a morphological entity. ${ }^{1}$ Yet, as already demonstrated, it is the recognition of the nature of an absent connection (Fig. 3), and its distinction from the imperforate valvar membrane (Fig. 4), which is the key to appreciation of much of the anatomic heterogeneity to be found in patients with atrioventricular valvar atresia. ${ }^{2}$ Another confounding problem, nonetheless, is very nature of the ventricular mass in such patients. In the past, we had argued that the heart itself in patients with classical tricuspid atresia was "univentricular". 3,4 In making this assertion, we were unequivocally wrong. Although the heart is functionally univentricular in the commonest form of this lesion, the anatomic arrangement is that of a big left ventricle along with a small rudimentary and incomplete right ventricle (Fig. 5). Our emphasis on the apparent morphological "univentricular" nature of such hearts, therefore, was misplaced. Despite this, there can be no question but that the concept of a functionally univentricular entity remains totally valid. Thus, the comparability between the ventricular mass in hearts with atrioventricular valvar atresia (Fig. 6), and that seen in patients with double inlet left ventricle (Fig. 7), is obvious and well established. ${ }^{5}$ In this review, we discuss all 


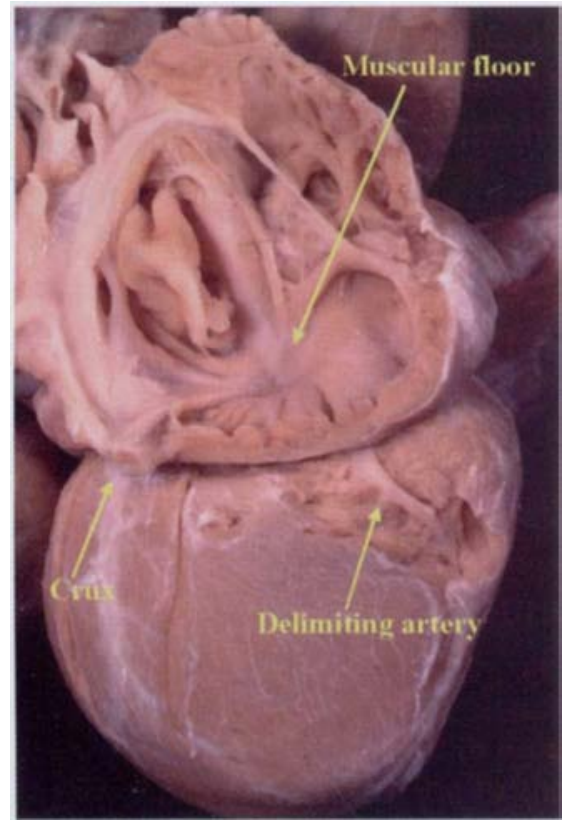

Figure 1.

This specimen with "classical" tricuspid atresia is seen from bebind, having removed the parietal wall of the right atrum. The essence of the malformation is complete absence of the right atrioventricular junction. Note the presence of the artery at the acute margin delimiting the posterior extent of the septum between the dominant left and the rudimentary right ventricle. The septum does not extend to the crux.

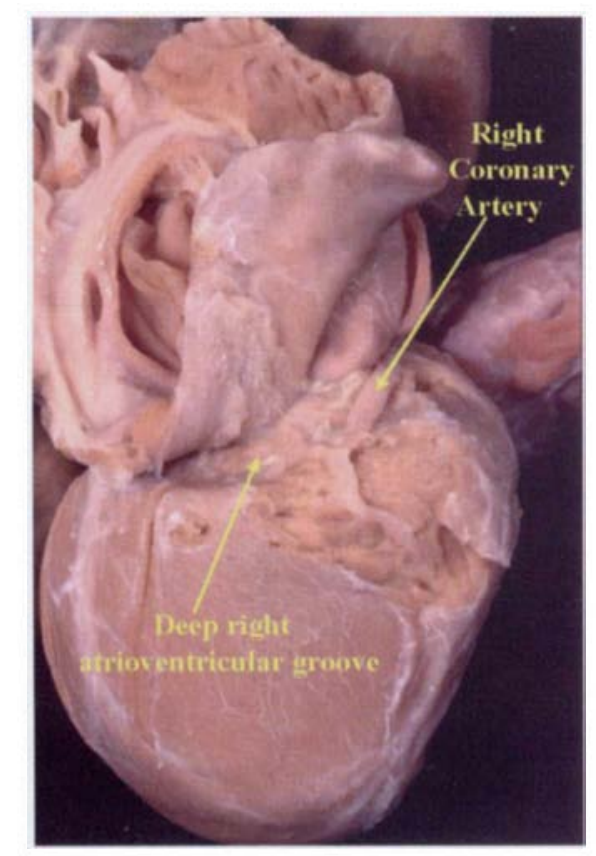

Figure 2.

The same beart as shown in Fig. 1. The muscular floor of the right atrium bas been stripped back from the ventricular mass, revealing the deep fibro-fatty atrioventricular groove which interposes between right atrium and the ventricular mass. these morphological problems. We show how use of a descriptive, rather than a nominative, approach to nomenclature is helpful in resolving the questions concerning the anatomic variability of patients with atrioventricular valvar atresia.

\section{Basic definitions of atrioventricular valvar atresia}

"Atresia" is a greek word. When translated literally, it means blockage of a natural channel of the body. In the normal heart, there are two such channels providing access from the atriums to the ventricles. These are guarded by the tricuspid and mitral valves, respectively. Thus, the normal heart possesses paired atrioventricular junctions (Fig. 8). Atresia of either of these channels can then be produced by one of two discrete morphological mechanisms. The commonest abnormality, irrespective of whether it involves the morphologically tricuspid or mitral valves, is to find complete absence not only of the valve itself, but also the area normally occupied by the muscular atrioventricular junction. The floor of the afflicted atrium is then exclusively muscular (Fig. 1), and is separated by the fibrofatty atrioventricular groove from the underlying ventricular chambers (Fig. 3). This arrangement is well demonstrated by cross-

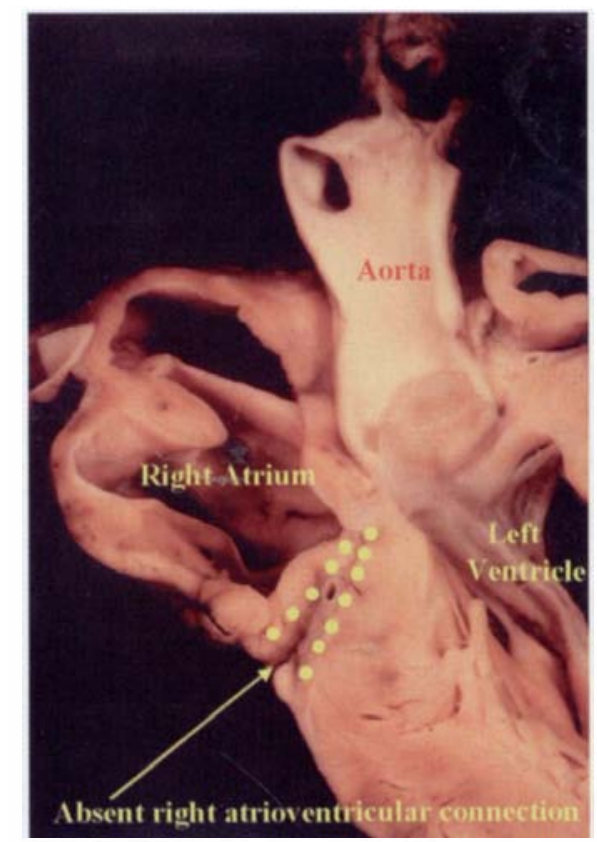

Figure 3.

This cut in four-chamber projection demonstrates absence of the right atrioventricular connection, highlighted by the dots, in tricuspid atresia. Note that the "dimple" points to the subaortic outflow tract of the left ventricle, and is the atrioventricular component of the membranous septum. 


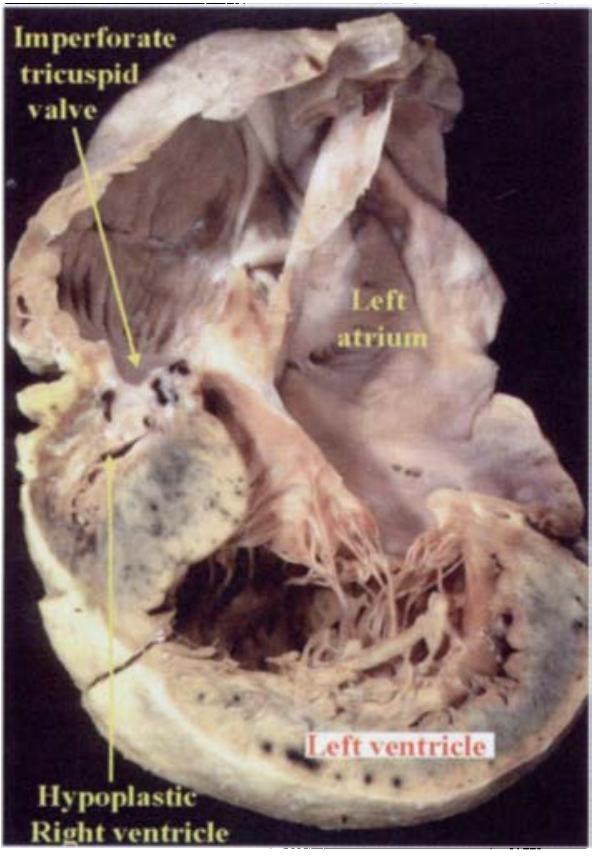

Figure 4.

This specimen has pulmonary atresia with intact ventricular septum, and concordant atroventricular connections. The tricuspid valve is imperforate, producing tricuspid atresia. Note the bypoplastic right atrioventricular junction blocked by the imperforate valvar membrane.

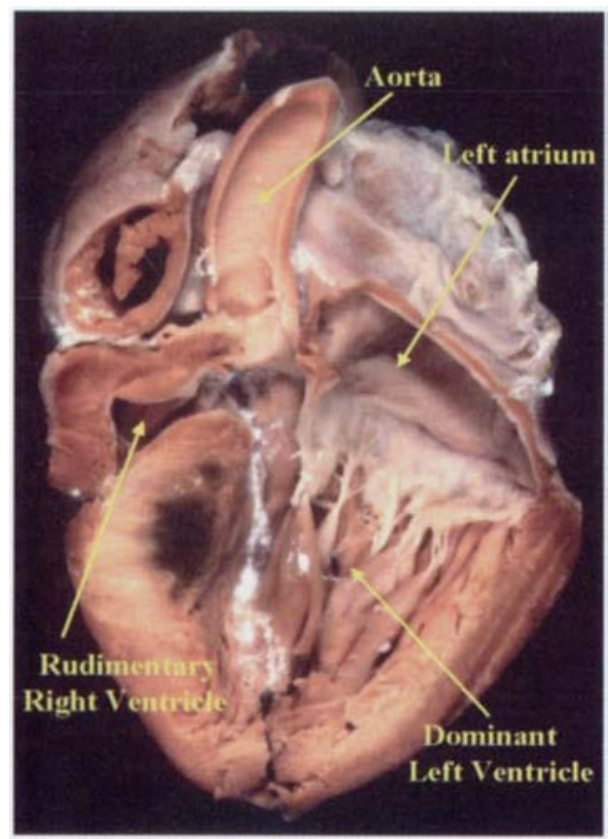

Figure 5.

In this specimen with tricuspid atresia, a long axis section shows the dominant left ventricle and the rudimentary right ventricle. Only the left atrium is connected to a ventricle (univentricular atrioventricular connection).

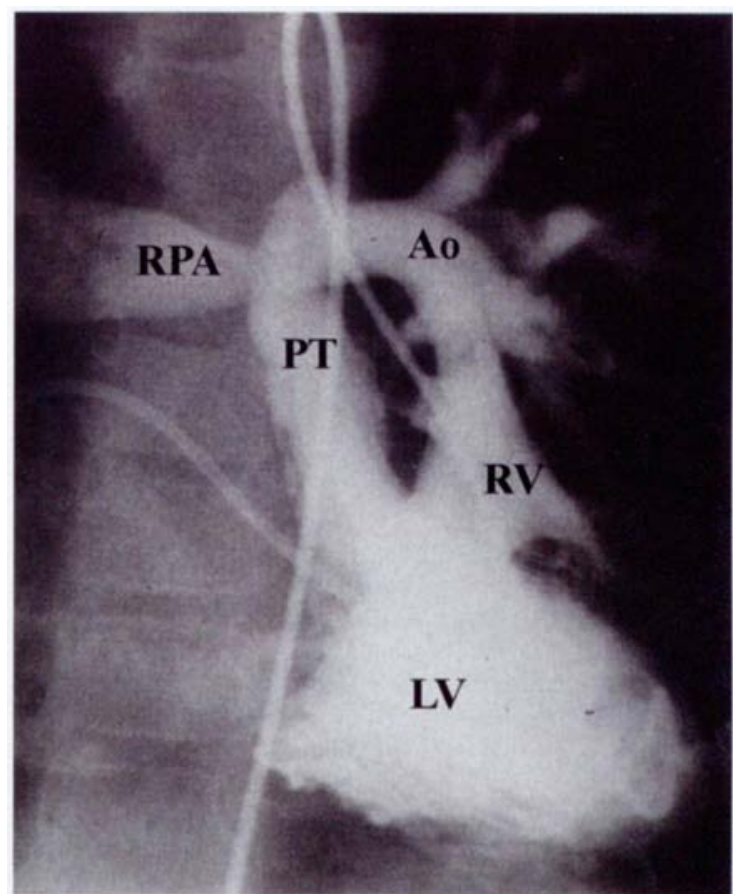

Figure 6.

This angiogram is from a patient with absent left atrioventricular connection, and with the left atrium connected to a dominant left ventricle. The rudimentary right ventricle, supporting the aorta, is left-sided. This is indicative of left hand ventricular topology. Had the valve developed between left atrium and right ventricle, it would bave been of tricuspid morphology.

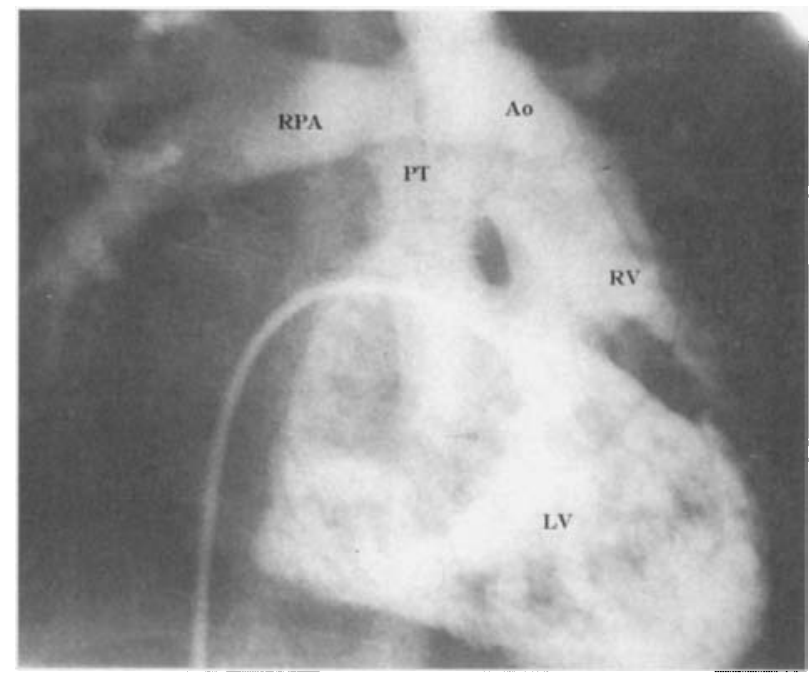

Figure 7.

In this patient, there is double inlet to the dominant left ventricle with rudimentary right ventricle in left-sided position and discordant ventriculo-arterial connections. The picture is directly comparable to that shown in Fig. 6. 
sectional echocardiography (Fig. 9). The pattern, accurately described as absence of one atrioventricular connection, means that, of necessity, one of the ventricles lacks totally its inlet component. It results, therefore, in one variant ${ }^{6}$ of univentricular atrioventricular connection (Figs 3,5). This arrangement is to be contrasted with the second, much rarer, anatomic lesion producing valvar atresia, namely presence of an imperforate valvar membrane (Fig. 4). An imperforate valve, perforce, must block a discrete atrioventricular junction. Such imperforate valves, therefore, can be found in the setting of biventricular atrioventricular connections (Fig. 4). The imperforate valve can also be found in the setting of double inlet ventricle, giving another example of univentricular atrioventricular connection (Fig. 10). The potential anatomic variability for imperforate valves, therefore, is considerably greater than for absence of one or other atrioventricular connection. It is the potential combinations of segmental connections which is responsible for the anatomic heterogeneity. ${ }^{7}$

\section{Sequential segmental analysis}

The variability to be found in patients with atrioventricular valvar atresia involves all segments of the heart. The different patterns at each level are then pertinent to the most appropriate way of describing the malformations. Since the basic effect of the valvar atresia is to block the return from one or other atrium to the ventricular mass, the arrangement of the atrial chambers themselves is the first important variant. For example, taking tricuspid atresia as a paradigm, the "classical" variant of this lesion blocks the direct return of systemic venous blood to the right ventricle. Typically, this produces atresia of the right-sided atrioventricular junction. In patients with mirrorimaged atrial arrangement, however, it is the leftsided atrium which is abnormal when there is tricuspid atresia. As we have already discussed, if the atrial chambers are arranged in usual fashion, but in a heart in which the ventricular mass is mirror-imaged, either absence or imperforateness of the left-sided atrioventricular junction can justifiably be described as tricuspid atresia, but now producing blockage of the pulmonary venous return (Fig. 11). And, in this setting, the ventricular mass (Fig. 6) is indistinguishable from classical double inlet left ventricle with left-sided rudimentary right ventricle (Fig. 7). Properly to diagnose and describe these malformations, therefore, it is best to account for variability initially at atrial level, then to dissect the structure of the atrioventricular junctions, and finally to combine this analysis with similar review of the potential variability at the ventriculo-arterial junctions, since the way the arterial trunks take origin from the ventricular mass will also markedly affect the clinical presentation.

\section{Variability at atrial level}

Most patients seen with atrioventricular valvar atresia will have usual atrial arrangement ("solitus"). In this setting, atresia of the right-sided atrioventricular junction, be it due to absence of the connection (Fig. 3) or an imperforate valvar membrane (Fig. 4), will block the direct return to the ventricles of the blood from the systemic venous tributaries. Left atrioventricular valvar atresia, in contrast, will block the direct egress of the pulmonary venous return. In most cases, but not all, the right-sided atrioventricular valve is actually or potentially of tricuspid morphology, while the abnormal left atrioventricular valve is an imperforate mitral valve, or would have been of mitral morphology had it been formed. These typical cases are traditionally described as tricuspid and mitral atresia, and are immediately recognisable. There is then considerable potential for complexity in the ventricular mass which, as we will see, also requires full segmental analysis. Complexity at the atrial level, in contrast, is rare. In the infrequent cases with mirror-imaged atrial arrangement, the patterns, as anticipated, are simply the reverse of the usual situation. Atrioventricular valvar atresia in the setting of isomerism, however, can produce problems in description. Thus, when the atrial appendages are isomeric, absence of an atrioventricular connection can produce comparable atrial anatomy on either the right or left side of the heart. The haemodynamic problem will then depend primarily on the precise venoatrial connections, which always require full description in the setting of isomerism.

Perhaps the major problem in providing accurate description at atrial level comes when the atrioventricular septum is deficient. This is because it can be very difficult to separate the rare entity of tricuspid atresia with straddling left atrioventricular valve (Fig. 12) from atrioventricular septal defect with common atrioventricular junction and so-called "double outlet left atrium". Similarly, it can be difficult to determine whether there is mitral atresia with straddling right valve (Fig. 13, right), or atrioventricular septal defect with "double outlet right atrium" (Fig. 13, left). As far as is possible, we use anatomic criterions to make this distinction. Thus, we have argued that the paradigm of the commonest form of atrioven- 


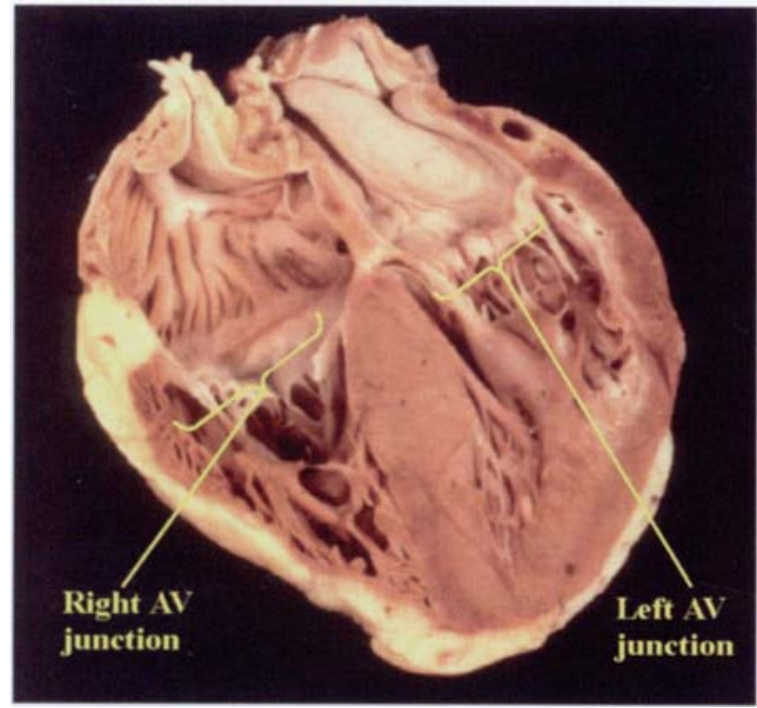

Figure 8.

This simulated four-chamber section of the normal beart reveals the presence of discrete and separate atrioventricular (AV) junctions for the right and left sides of the beart.

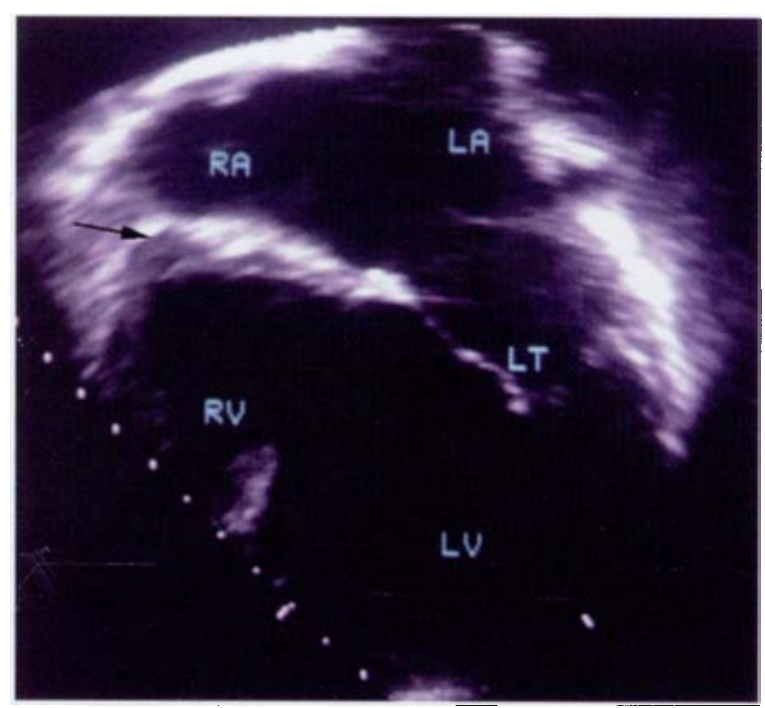

Figure 9.

The echocardiographic appearance of classical tricuspid atresia. Note the extensive fibro-fatty atrioventricular groove interposed between the floor of the right atrium and the rudimentary and incomplete right ventricle (arrowed). This is indicative of absence of the right atrioventricular connection. Abbreviations: $R A-$ right atrium; $L A$ - left atrium; $R V$ - right ventricle; $L V$ - left ventricle; $L T$-open left atrioventricular valve. The abbreviations are also used for subsequent echocardiograms.

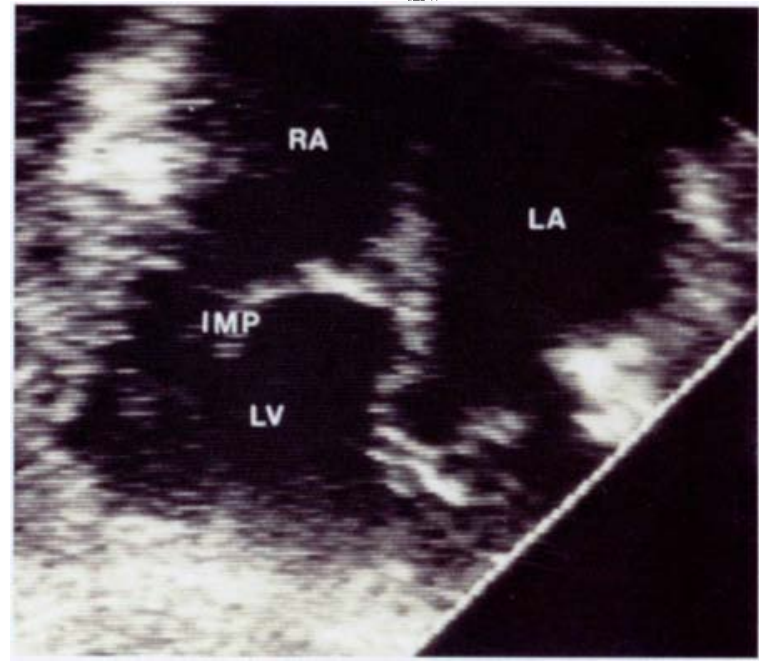

Figure 10.

In this echocardiographic section, it can be seen that the right atrioventricular connection is formed, but is blocked by an imperforate valvar membrane (IMP). The left atrioventricular valve is open, and both valves are exclusively connected to the dominant left ventricle. The section shows double inlet left ventricle with tricuspid atresia produced by an imperforate valvar membrane. The atrioventricular connections are univentricular despite the presence of the imperforate valve. Compare with Fig. 9.

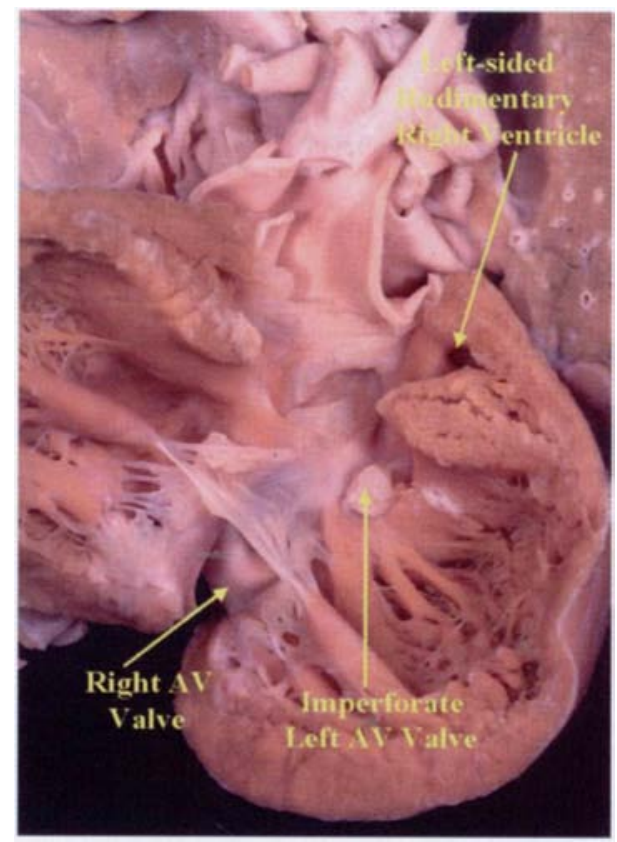

Figure 11.

This specimen shows double inlet left ventricle with an imperforate left atrioventricular $(A V)$ valve. The rudimentary right ventricle is leftsided, indicating left-band ventricular topology, and suggesting that the imperforate valve is of tricuspid morphology. 
tricular septal defect is the common atrioventricular junction. ${ }^{8}$ This feature, namely the common junction, is lacking when one atrioventricular connection is absent (Fig. 12). On this basis, most cases can readily be assigned to the categories of absent connection or common junction. When one connection is absent, the straddling and overriding valve will perforce be of right or left morphology, and not common. The atrioventricular connection will accurately be described as uniatrial but biventricular. In contrast, when there is a common junction, the atrioventricular connections will be biatrial, albeit draining predominantly from one or other atrium. But it is also well recognised that congenital heart malformations represent spectrums of abnormality. Thus, when an "ostium primum" defect is recognised as providing the exit from one atrium (Fig. 14), then the other atrium continues to drain to the ventricular mass through a common atrioventricular junction. If the "ostium primum" defect becomes increasingly small, at some point it could block off completely the atrium draining through it. Would the straddling common valve extending into both ventricles be any different morphologically from a straddling right valve (Fig. 15) if the "ostium primum" in this spectrum closed spontaneously? Furthermore, it is easy for the morphologist to argue that, properly to define tricuspid atresia, it is necessary to find the atrial septum walling off the right atrium from the left atrioventricular junction (Fig. 12). It may be possible, however, to find hearts in which the right atrioventricular connection has failed to form when the left atrioventricular junction is guarded by a trifoliate left -atrioventricular valve, and the ventricular mass shows the typical morphology of an atrioventricular septal defect. In the presence of an "ostium primum" defect, this lesion would not fit the anatomic definition proposed above for "tricuspid atresia". Yet the anatomy observed would be exactly as expected for formation of half of a common atrioventricular junction. Indeed, this arrangement has now been consistently recognise $\mathrm{d}^{9}$ in mice known to have deficient atrioventricular septation (Fig. 16). It seems that, however hard we try to provide exclusive anatomic definitions, the heterogeneity discovered in malformed human hearts defies our best efforts to achieve consistency. We must recognise the validity of various interpretations of the abnormal morphology. Careful and complete description remains the best solution to these rare combinations of malformations (see below).

\section{Variability at the atrioventricular junctions}

The basic variation found at the atrioventricular junctions has already been described, namely the differentiation of absence of one atrioventricular connection (Fig. 3) from an imperforate valvar membrane (Fig. 4). This variability is itself inextricably linked with further variability in the ventricular mass, but once more the heterogeneity is considerable. Completely to account for all the variations in atrioventricular valvar atresia, it is necessary to permutate the potentials for variability at atrial level, within the atrioventricular junction, within the ventricular mass, and at the ventriculo-arterial junctions. In our opinion, it is no longer possible to account for all this variation simply in terms of "tricuspid" and "mitral" atresia. Thus, at first sight it seems possible to categorise patients with tricuspid atresia into those with univentricular atrioventricular connection, when one connection is absent, as opposed to those with biventricular connections when the tricuspid valve is formed but imperforate. This simple division fails when it is recognised that some patients with double inlet left ventricle can have

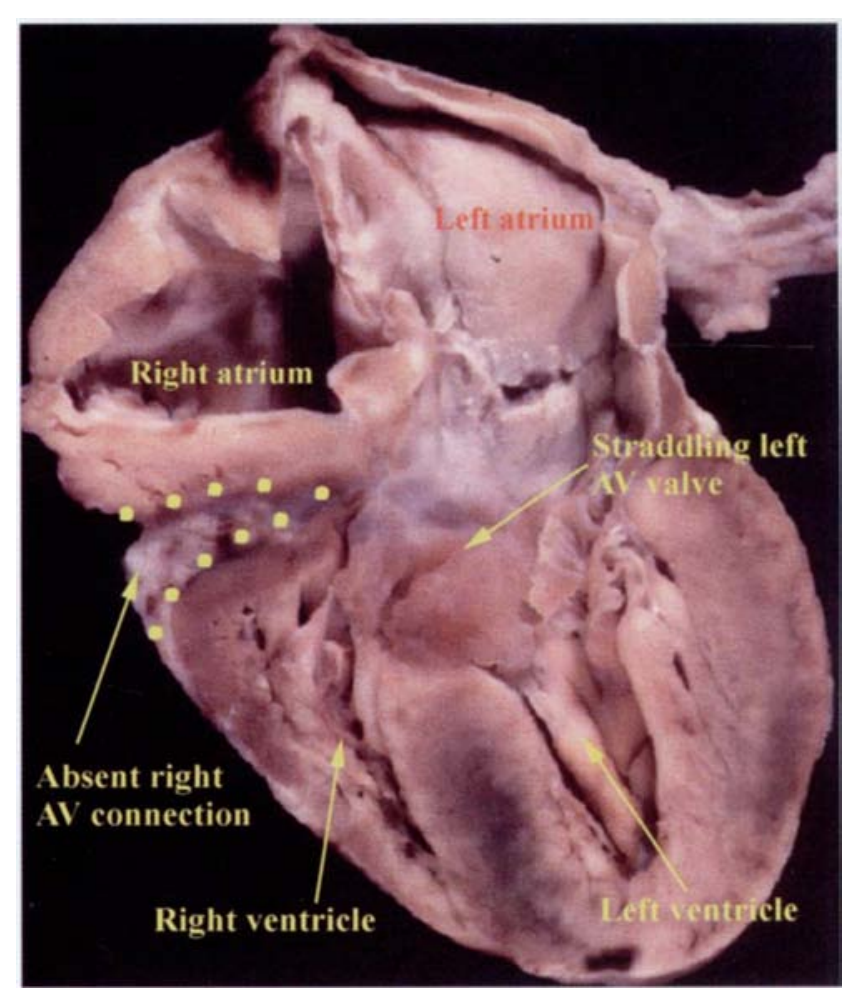

Figure 12.

In this specimen, sectioned in four-chamber fashion, there is absence of the right atrioventricular connection, but the left atrioventricular valve straddles so as to be connected in both ventricles. This produces an atrioventricular connection wbich is uniatrial but biventricular. 


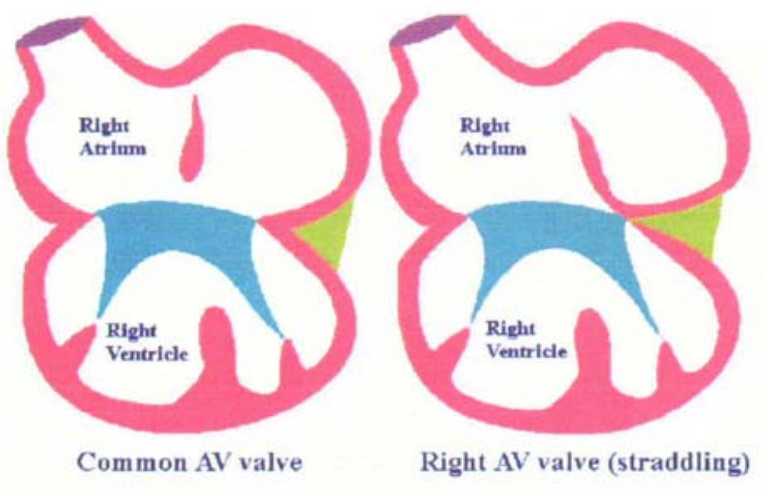

Figure 13.

This cartoon illustrates the potential spectrum which exists between, on the one band (left panel) a common atrioventricular junction and, on the other band (right panel), absence of the left atrioventricular connection with straddling right atrioventricular valve. The distinction between the two entities depends on whether the atrial septum walls off the left atrium from the atrioventricular junction.

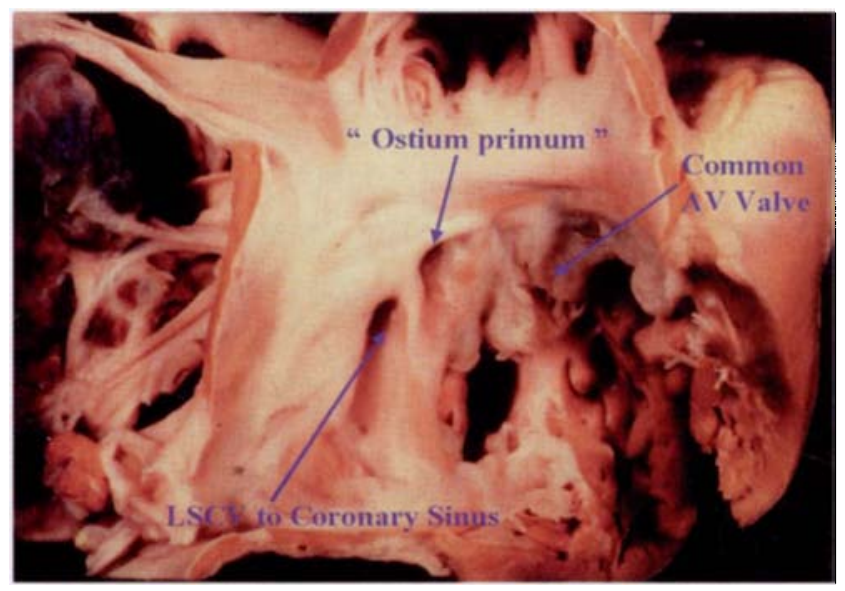

Figure 14.

In this beart, shown from the right atrium, there is a common atrioventricular $(A V)$ valve equally shared between the right and left ventricles (see Fig. 13, left panel). The only exit for blood from the left atrium is through an "ostium primum" defect. Note that a persistent left superior caval vein (LSCV) drains through an enlarged coronary sinus.

an imperforate atrioventricular valve (Fig. 10). Hence, the imperforate valve co-exists with the univentricular connection. Furthermore, this arrangement with double inlet and an imperforate right valve can be found when the incomplete right ventricle is either right-sided or left-sided. Would it help, when the ventricle is left-sided, to describe the patient as having mitral atresia, when the imperforate right atrioventricular valve produces the clinical picture of tricuspid atresia? Surely a full account of the segmental arrangement is needed?

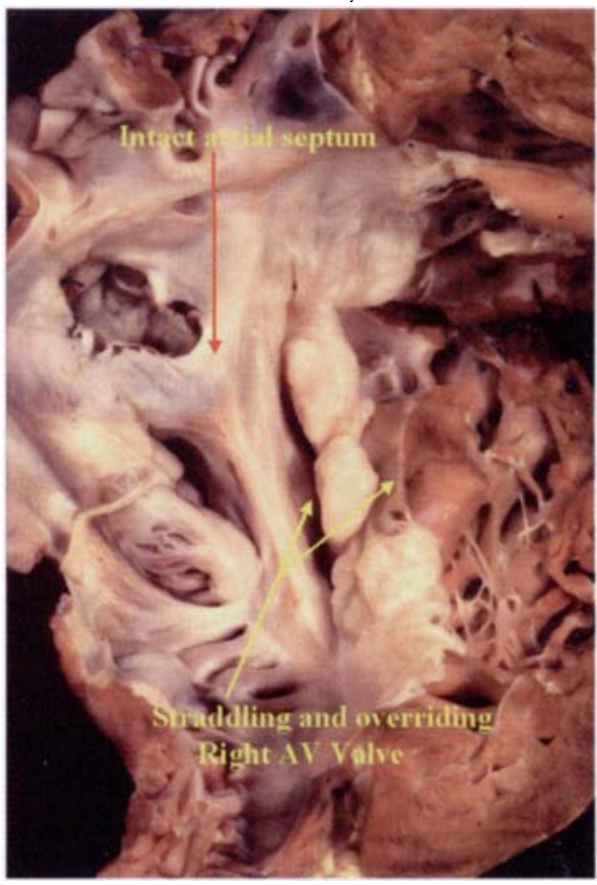

Figure 15.

In this specimen, the atrial septum walls off the left atrium from the ventricular mass (see Fig. 13, right panel). The atrioventricular $(A V)$ valve, therefore, is a right valve, but it connects the right atrium to both the left and the right ventricles. It is difficult to distinguish the morphology from the common valve shown in Fig. 14.

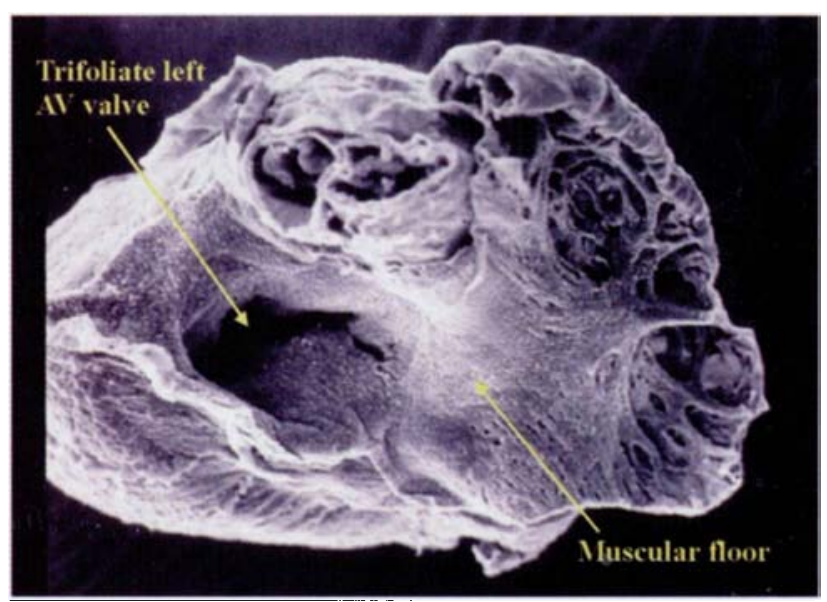

Figure 16.

This scanning electron microscope shows a heart from a mouse with trisomy 16. The floor of the right atrium is muscular, and a trifoliate left atrioventricular $(A V)$ valve connects the left atrium to the left ventricle. This beart had an "ostium primum" defect. Reproduced by kind permission of Dr Sandra Webb and Professor Nigel Brown of St George's Hospital Medical School.

The distinction of univentricular versus biventricular connections is also found wanting in those unusual patients considered above who have 
unequivocal absence of one atrioventricular connection, but with straddling of the solitary atrioventricular valve (Fig. 12). Here again, it is essential to give a full segmental description, since the anatomic heterogeneity to be encountered defies the potential to describe these lesions simply in terms of "mitral" or "tricuspid" atresia.

\section{Variability in the ventricular mass}

Almost all patients with atrioventricular valvar atresia will possess one big and one small ventricle. Very rarely, patients may be encountered when one atrioventricular connection is absent and there is a solitary ventricle present of indeterminate apical morphology (Fig. 17). These are the only patients with atrioventricular valvar atresia who have truly univentricular hearts. In the remaining greater majority of patients, the ventricular mass is functionally univentricular. Anatomically, nonetheless, it is made up of one big and one small ventricle. Most usually, the big ventricle is of left morphology, while the small right ventricle is rudimentary and incomplete. This is the arrangement seen in so-called "classical" tricuspid atresia, but also when the left-sided atrioventricular connection is absent and the rudimentary right ventricle is leftsided. The atrial anatomy so typical of "classical" tricuspid atresia, however, can be replicated when the left atrium is connected to a dominant right ventricle, and the rudimentary and incomplete left ventricle is found posteriorly and to the right (left hand ventricular topology - Fig. 18). Further variations in ventricular morphology are found when the atresia is the consequence of an imperforate valve. If the valve is imperforate in the setting of double inlet ventricle, then the ventricular morphology is exactly as expected for absence of an atrioventricular connection. When the atrioventricular connections are biventricular, the ventricular mass is still typically unbalanced, but both ventricles are normally constituted, albeit that the one with an imperforate valve is hypoplastic (Fig. 19). This pattern of imperforate atrioventricular valve is typically seen when the ventricular septum is intact (Fig. 4), and the outflow tract is additionally atretic. The example shown in Figure 19 , nonetheless, has a co-existing ventricular septal defect. It is also possible to envisage the situation in which an imperforate atrioventricular valve could be found in a heart with ventricles of equal size, potentially permitting surgical excision of the abnormal valve and replacement with a valvar prosthesis. We have seen the potential for this only in patients with coexisting Ebstein's malformation (Fig. 20), and then associated malformations are usually sufficiently severe to preclude any attempt at biventricular repair.

It follows from the above discussion that, although most cases with atrioventricular valvar atresia have a ventricular septal defect, some patients can have intact ventricular septums. In those with deficient ventricular septation, the

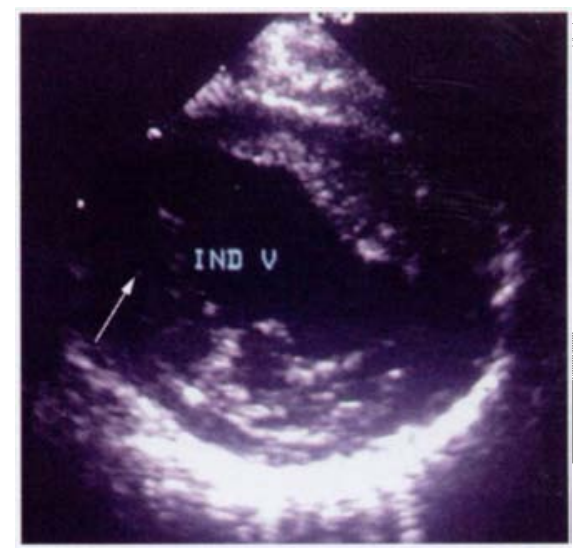

Figure 17

This echocardiographic section shows absence of the right atrioventricular connection (arrowed - tricuspid atresia) in a patient with a solitary ventricle of indeterminate morphology (IND V).

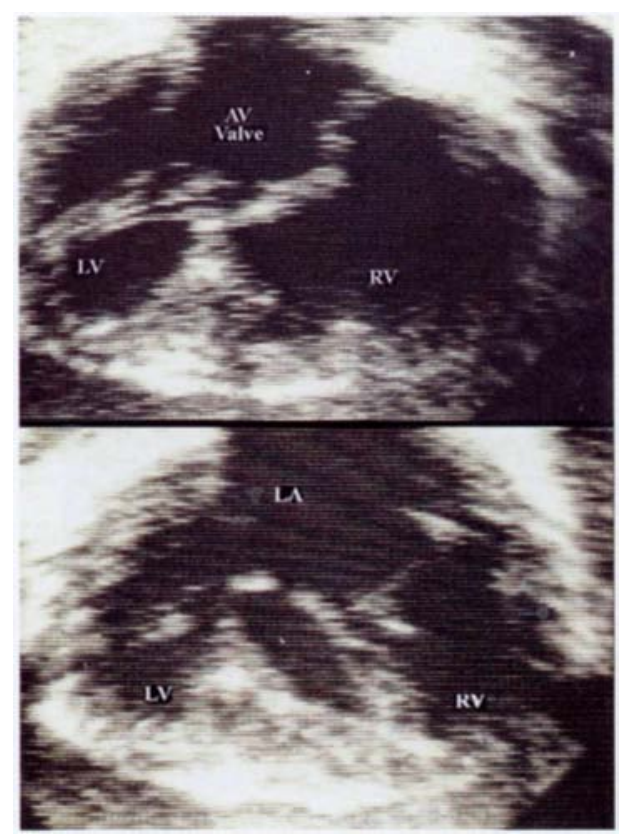

Figure 18.

These panels show (upper) absence of the right atrioventricular connection, but with the left atrium connected to a dominant right ventricle. The rudimentary left ventricle is posterior and to the right (left band topology). The lower panel shows that the left atrioventricular valve straddles and overrides the ventricular septum. The right valve in this patient would have been of tricuspid morphology, yet the clinical picture is that of classical tricuspid atresia. 


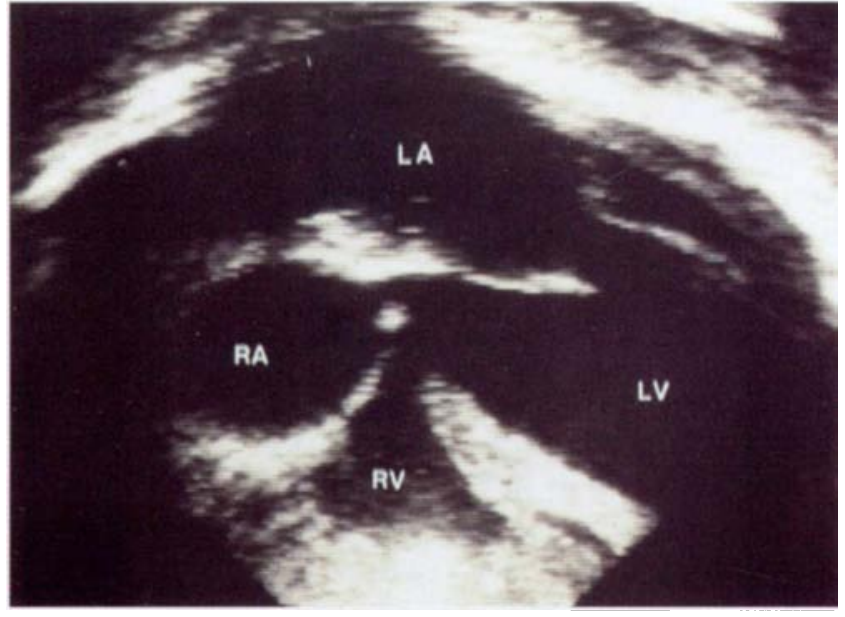

Figure 19.

This echocardiograpbic four-chamber section shows an imperforate (IMP) right atrioventricular valve in a patient with concordant atrioventricular connections. The mitral valve is open. Compare with Fig. 4.

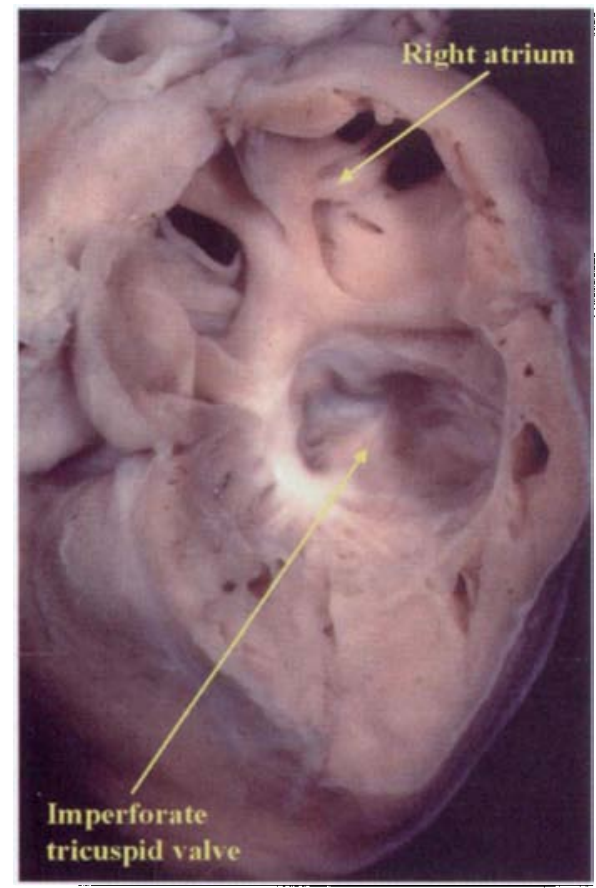

Figure 20.

In this specimen, the imperforate right atrioventricular valve in a patient with concordant atrioventricular connections shows Ebstein's malformation. It as only in this setting that we bave encountered imperforate valves blocking an atrioventricular junction potentially of suitable magnitude to permit the insertion of a right atrioventricular valve.

morphology of the defect reflects the ventricular morphology. Thus, almost always those with dominant left and rudimentary right ventricles have muscular ventricular septal defects. Typically, these defects are positioned between the apical ventricular septum and the outlet septum. They can be of variable size, but show a tendency towards spontaneous closure with growth. This produces subpulmonary obstruction when the ventriculo-arterial connections are concordant, but subaortic obstruction with discordant ventriculoarterial connections (Fig. 21). The structure of the defect is basically comparable in these situations, although the subpulmonary infundibulum is usually much longer than the subaortic one. ${ }^{5}$ The basic arrangement, and the disposition of the conduction tissues, is also comparable irrespective of the atrioventricular connection, and irrespective of the location of the rudimentary and incomplete right ventricle (Fig. 22). It is possible to find apical muscular defects in this setting, and also for the defect to be doubly committed and juxta-arterial when the muscular outlet septum is lacking. Perimembranous defects, in contrast, do not exist in hearts with dominant left and rudimentary and incomplete right ventricles. Perimembranous defects are found only when there are biventricular atrioventricular connections, or else when the right ventricle is dominant.

\section{Variability at the ventriculo-arterial junctions}

Traditionally, tricuspid atresia was divided into patients with concordant as opposed to discordant ventriculo-arterial connections, with further subdivision according to the size of the ventricular

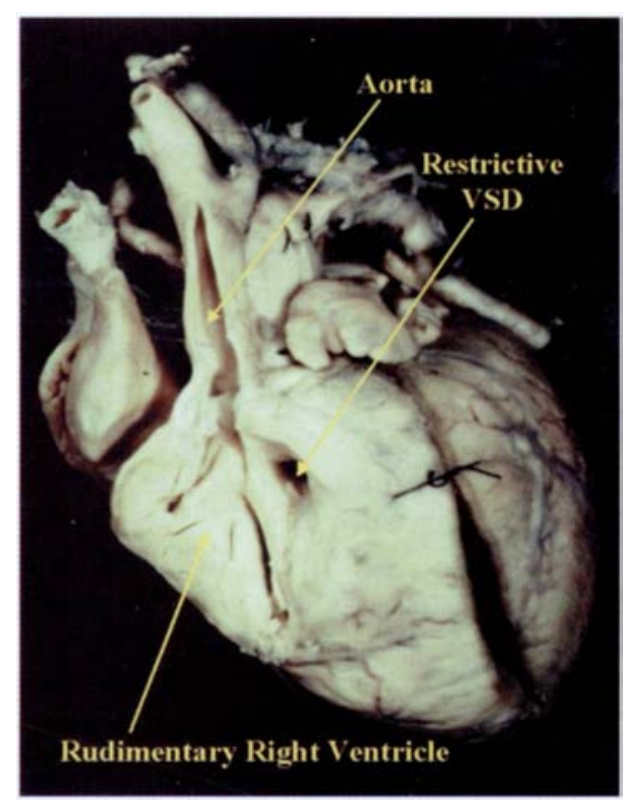

Figure 21.

This beart shows tricuspid atresia with discordant ventriculo-arterial connections. Restriction at the level of the ventricular septal defect (VSD) produces subartic obstruction. 


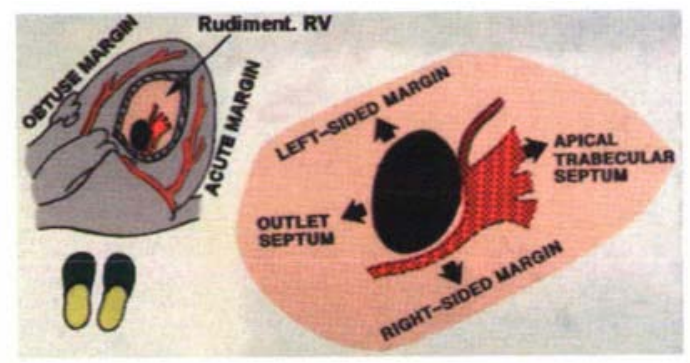

Figure 22.

Whenever there is univentricular connection to a dominant left ventricle, irrespective of the precise atrioventricular connection or the ventriculo-arterial connections, the conduction axis is disposed as shown in the cartoon. The inset sbows the view of the rudimentary right ventricle as would be obtained by the surgeon in the operating room. It is the septal component adjacent to the obtuse margin which can safely be resected to enlarge the defect.

septal defect. ${ }^{10}$ Mitral atresia most usually is seen as part of the hypoplastic left heart syndrome, or with double outlet right ventricle. With increasing experience, it has become plain that any type of ventriculo-arterial connection can accompany the various forms of atrioventricular valvar atresia. Some have attempted to legislate for this increased variability in tricuspid atresia by expanding the traditional alpha-numeric classification, ${ }^{11}$ but such categorisations become increasingly unwieldy as more and more variations are included. ${ }^{12}$ Because of this, it remains our preference to use a descriptive approach. Thus, we can describe in simple fashion, for example, those who have tricuspid atresia associated with common arterial trunk, or with double outlet from the dominant left ventricle, or any other variation.

\section{Summation of variability}

With increasing experience, it is becoming evident that all potential variations in atrioventricular valvar atresia will, eventually, be encountered in the clinical setting. Thus, imperforate atrioventricular valves, or absence of one atrioventricular connection, can be found with any arrangement of the atrial appendages. An imperforate valve can be found in the setting of double inlet ventricle, or with any of the possible biventricular atrioventricular connections. Absence of one atrioventricular connection can, very rarely, be found in the pattern producing the uniatrial but biventricular atrioventricular connection. Absence of either the right-sided or left-sided atrioventricular connection, or an imperforate right or left atrioventricular valve, can be found in all variants of right hand or left hand ventricular topology, or even when there is a solitary ventricle of indeterminate morphology. All possible ventriculo-arterial connections can then be associated with these already huge combinations of anomalies. The only way realistically of catering for this heterogeneity is to use a descriptive approach to diagnosis and categorisation, and to assess the potential for variability at each segmental level.

\section{Acknowledgements}

This work was supported by the British Heart Foundation, together with the Joseph Levy Foundation.

\section{References}

1. Rao PS. Terminology: Is Tricuspid atresia the correct term to use? In: Rao PS, ed. Tricuspid Atresia. 2nd Ed. Futura Publishing Company Inc, Mount Kisco, New York. 1999:3-16.

2. Orie JD, Anderson C, Ettedgui JA, Zuberbuhler JR, Anderson RH. Echocardiographic-anatomical correlations in tricuspid atresia. J Am Coll Cardiol 1995;26:750-758.

3. Anderson RH, Wilkinson JL, Gerlis LM, Smith A, Becker AE. Atresia of the right atrioventricular orifice. Br Heart $\mathrm{J}$ 1977;39:414-428.

4. Anderson RH, Becker AE, Macartney FJ, Shinebourne EA, Wilkinson JL, Tynan MJ. Is "tricuspid atresia" a univentricular heart? Pediatr Cardiol 1979;1:51-56.

5. Deanfield JE, Tommasini G, Anderson RH, Macartney FJ. Tricuspid atresia: an analysis of the coronary artery distribution and ventricular morphology. Br Heart J 1982;48:485-492.

6. Anderson RH, Macartney FJ, Tynan M, Becker AE, Freedom RM, Godman MJ, Hunter S, Quero Jim,nez M, Rigby ML, Shinebourne EA, Sutherland GR, Smallhorn JF, Soto B, Thiene G, Wilkinson JL, Wilcox BR, Zuberbuhler JR. Univentricular atrioventricular connection: the single ventricle trap unsprung. Pediatr Cardiol 1983;4:273-280.

7. Anderson RH, Rigby MI. The morphologic heterogeneity of "tricuspid atresia". Int J Cardiol 1987;16:67-73.

8. Anderson RH, Ho SY, Falcao S, Daliento L, Rigby ML. The diagnostic features of atrioventricular septal defect with common atrioventricular junction. Cardiol Young 1998;8:33-49.

9. Webb S, Brown NA, Anderson RH. Cardiac morphology at late fetal stages in the mouse with trisomy 16: consequences for different formation of the atrioventricular junction when compared to humans with trisomy 21. Cardiovasc Res 1997;34:515-524.

10. Edwards JE, Burchell HB. Congenital tricuspid atresia: a classification. Med Clin North Am 1949;33:1177-1196.

11. Tandon R, Edwards JE. Tricuspid atresia. A re-evaluation and classification. J Thorac Cardiovasc Surg 1974;67:530-542.

12. Rao PS. A unified classification for tricuspid atresia. Am Heart J 1980;99:799-804. 